\title{
Inflammation marker ESR is effective in predicting outcome of diffuse large B-cell lymphoma
}

\author{
Shuang Wu', Ye Zhou', Hai-Ying Hua', Yan Zhang ${ }^{1}$, Wen-Yan Zhu' ${ }^{1}$ Zhi-Qing Wang ${ }^{1}$, Jin Li ', Hua-Qiang Gao ${ }^{1}$,
} Xiao-Hong $\mathrm{Wu}^{2}$, Ting-Xun Lu ${ }^{2^{*}}$ (D) and Dong Hua ${ }^{2^{*}}$

\begin{abstract}
Background: Systemic inflammation has been implicated in cancer development and progression. This study examined the best cutoff value of erythrocyte sedimentation rate (ESR) in diffuse large B-cell lymphoma (DLBCL) patients.

Methods: The relationship between ESR and clinical characteristics was analyzed in 182 DLBCL patients from 2006 to 2017. The log-rank test, univariate analysis, and Cox regression analysis were applied to evaluate the relationship between ESR and survival. An ESR of more than $37.5 \mathrm{~mm} /$ hour was found to be the optimal threshold value for predicting prognosis.

Results: ESR was associated with more frequent advanced Ann Arbor stage, poorer performance status, elevated lactate dehydrogenase level, the presence of B symptoms, high-risk International Prognostic Index (IPI 3-5), more extranodal involvement (ENI $\geq 2$ ), non-germinal-center B-cell (non-GCB) subtypes, and more frequent Myc protein positivity. Shorter overall survival (OS) and progression-free survival (PFS) were found for patients with higher ESRs. Multivariate analysis demonstrated that ESR level is an independent prognostic factor of both OS and PFS. In addition, dynamic changes in ESR are valuable in assessing curative effect and predicting disease recurrence.
\end{abstract}

Conclusion: High ESR in DLBCL patients indicated unfavorable prognosis that may require alternative treatment regimens.

Keywords: Diffuse large B-cell lymphoma, Erythrocyte sedimentation rate, Prognosis, Survival

\section{Background}

Diffuse large B-cell lymphoma (DLBCL) is one of the most prevalent non-Hodgkin lymphomas (NHLs) which are heterogeneous both clinically and genetically. With current immunochemotherapy, approximately 30\% of patients fail chemotherapy [1].

Despite recent progress in understanding the molecular biology of DLBCL, clinical risk factor models are still used to identify patients who are unlikely to be cured with current therapy. The most widely used model is the International Prognostic Index proposed by the National

\footnotetext{
* Correspondence: lutingxun@163.com; wx89211@163.com

${ }^{2}$ Department of Oncology, Affiliated Hospital of Jiangnan University, Wuxi 214000, Jiangsu, People's Republic of China

Full list of author information is available at the end of the article
}

Comprehensive Cancer Network (NCCN-IPI), which is based on clinical parameters [2].

Although the NCCN-IPI is robust and confirmed to be reproducible [3-5], the link between the included clinical parameters and underlying biology or targeted treatment remains to be defined [6]. Therefore, molecular markers with great prognostic significance in DLBCL are being used, but it is costly and most rely on tissue. Therefore, alternative readily available prognostic characteristics with low clinical cost are greatly needed to improve risk assessment for individual patients.

There is thus a need for powerful, independent prognostic and predictive factors that can be analyzed using non-invasive methods such as with the patient's serum that can enable individualized treatment modalities for patients with poor prognosis.

(c) The Author(s). 2018 Open Access This article is distributed under the terms of the Creative Commons Attribution 4.0 International License (http://creativecommons.org/licenses/by/4.0/), which permits unrestricted use, distribution, and 
Cancer has been regarded as a wound that does not heal, and inflammation has long been recognized as being important, playing a critical role in various processes related to cancer progression [7]. Most tumors are highly infiltrated by immune cells, including macrophages, neutrophils and lymphocytes. Thus, inflammation and host immune response-related markers may be relevant as biological markers of DLBCL progression [8], although they have not been investigated to a great extent and not with respect to their relevance for the survival of patients with DLBCL.

In the past, a number of laboratory markers have been proposed for prognosis in DLBCL. Among these, systemic inflammation has been implicated in cancer development and progression $[9,10]$. ESR is routinely measured in clinical practice for inpatients, as an indicator of infection, sepsis, or autoimmunity and malignancy as well [11-17]. Increased ESR values have, for example, been found to correlate with overall poor prognosis in Hodgkin's disease, breast, glioma, gastric and colorectal, prostate and renal cell carcinoma, as well as in Mycosis fungoides [14, 1618]. It was believed that elevated ESR indicates a greater risk of NHLs [8]. However, the prognostic value of elevated ESR in DLBCL patients has not been systematically explored. In this study, therefore, we analyzed the clinical significance and the prognostic value of elevated ESR in DLBCL patients.

\section{Methods}

\section{Selection of patients}

According to the 2016 World Health Organization (WHO) classification, we reviewed the medical records of patients who were diagnosed with de novo DLBCL at the third affiliated hospital of Nantong University and affiliated Hospital of Jiangnan University from 2006 to 2017. Only patients treated with R-CHOP (rituximab plus cyclophosphamide, doxorubicin, vincristine, and prednisone) or R-CHOP-like chemotherapy were included. Patients with primary central nervous system lymphoma, transformed NHL, post-transplant lymphoproliferative disorders, primary mediastinal B-cell lymphoma, and HIV-positive DLBCL were excluded from the study. In addition, patients with clinical evidence of anemia, chronic kidney disease, congestive heart failure, acute infection or chronic inflammatory disease were also excluded [12]. A total of 182 patients with DLBCL ultimately qualified for the study.

\section{Cutoff ESR value}

The optimal ESR cutoff value was $37.5 \mathrm{~mm} /$ hour as determined by X-tile software (Additional files 1 and 2: Figures S1 and S2).

\section{Immunohistochemistry}

Immunohistochemistry was performed on 4- $\mu \mathrm{m}$ FFPE sections. Antibodies used in the study were CD20 (clone L26, Abcam, cutoff: 30\%), CD10 (clone 56C6, Dako, cutoff: 30\%), MUM1 (clone MUM1p, Dako), Bcl6 (clone LN22, Dako, cutoff: 30\%), Myc (clone Y69; Abcam, cutoff: 40\%) and Bcl2 (clone 124; Dako, cutoff: 50\%). Cutoff scores for each antibody were described previously $[2,19]$.

\section{Statistical analysis}

Overall survival (OS) and progression free survival (PFS) were defined as in Cheson 2014 [20]. Survival curves were plotted using Kaplan-Meier method and were compared by log-rank test. Statistical analysis was performed using SPSS software, version 20.0. The Chi-squared and Fisher exact tests were used to determine differences in frequencies between groups. Cox regression model and multivariate analyses were performed in this study. For all the tests, a probability value of less than 0.05 (2-sided) was considered statistically significant.

\section{Results}

\section{Patients' characteristics}

The median age of the whole cohort was 55 years (range: 22 to 85 ). The prevalence of elevated ESR was 33.0\% (60/182). The baseline clinical parameters of patients are presented in Table 1.

\section{Association between clinical features and ESR}

In the whole cohort, ESR positivity was significantly associated with more frequent advanced Ann Arbor stage $(p=0.0002)$, poorer performance status (PS) $(p<0.0001)$, elevated LDH level $(p<0.0001)$, presence of B symptoms

Table 1 The clinical characteristics of the182 patients of DLBCL

\begin{tabular}{ll}
\hline Characteristics & No. of cases (\%) \\
\hline Age (years) & \\
$\quad \leq 60$ & $114(62.6)$ \\
Male & $110(60.4)$ \\
Stage III-IV & $111(61.0)$ \\
Elevated ESR & $61(33.5)$ \\
Elevated LDH & $84(46.2)$ \\
ECOG PS $\geq 2$ & $30(16.5)$ \\
ENI $\geq 2$ & $45(24.7)$ \\
IPI score of 3-5 & $49(26.9)$ \\
B symptoms & $85(46.7)$ \\
COO (Hans) & \\
GCB & $73(40.1)$ \\
\hline Abbrevidions: COO: cell of orign; DLBCL: dffuse lare B-cellym
\end{tabular}

Abbreviations: COO: cell of origin; DLBCL: diffuse large B-cell lymphoma; $E C O G$ PS: performance status of Eastern Cooperative Oncology Group; ENI: extranodal involvement; ESR: erythrocyte sedimentation rate; GCB: germinalcenter B-cell type; IPI: International Prognostic Index; LDH: lactate dehydrogenase 
$(p<0.0001)$, high-risk IPI (IPI 3-5) $(p<0.0001)$, more extranodal involvement $(\mathrm{ENI} \geq 2) \quad(p=0.024)$, non-GCB subtypes $(p=0.0004)$ and more frequent Myc protein positivity $(p=0.006)$ (Table 2$)$.

Table 2 Associations between clinical features and ESR

\begin{tabular}{|c|c|c|c|}
\hline \multirow[t]{2}{*}{ Characteristics } & $\mathrm{ESR}^{+}$ & $\mathrm{ESR}^{-}$ & $P$ value \\
\hline & \multicolumn{3}{|c|}{ No. of cases (\%) } \\
\hline \multicolumn{4}{|l|}{ Age (years) } \\
\hline$\leq 60$ & 37 & 77 & 0.849 \\
\hline$>60$ & 23 & 45 & \\
\hline \multicolumn{4}{|l|}{ Sex } \\
\hline Male & 36 & 74 & 0.932 \\
\hline Female & 24 & 48 & \\
\hline \multicolumn{4}{|l|}{ Stage } \\
\hline III-IV & 48 & 63 & 0.0002 \\
\hline$|-| \mid$ & 12 & 59 & \\
\hline \multicolumn{4}{|l|}{ Myc } \\
\hline Positive & 28 & 32 & 0.006 \\
\hline Negative & 32 & 90 & \\
\hline \multicolumn{4}{|l|}{ ECOG PS } \\
\hline$\geq 2$ & 20 & 10 & $<0.0001$ \\
\hline$<2$ & 40 & 112 & \\
\hline \multicolumn{4}{|l|}{$\mathrm{LDH}$} \\
\hline Over ULN & 47 & 37 & $<0.0001$ \\
\hline normal & 13 & 85 & \\
\hline \multicolumn{4}{|l|}{ ENI } \\
\hline$\geq 2$ & 21 & 24 & 0.024 \\
\hline$<2$ & 39 & 98 & \\
\hline \multicolumn{4}{|l|}{$\mathrm{BCl} 2$} \\
\hline$\geq 70 \%$ & 30 & 56 & 0.603 \\
\hline$<70 \%$ & 30 & 66 & \\
\hline \multicolumn{4}{|l|}{$\mid \mathrm{PI}$} \\
\hline $3-5$ & 31 & 19 & $<0.0001$ \\
\hline $0-2$ & 29 & 103 & \\
\hline \multicolumn{4}{|l|}{ B symptoms } \\
\hline Positive & 43 & 42 & $<0.0001$ \\
\hline Negative & 17 & 80 & \\
\hline \multicolumn{4}{|l|}{ COO (Hans) } \\
\hline GCB & 13 & 60 & 0.0004 \\
\hline Non-GCB & 47 & 62 & \\
\hline \multicolumn{4}{|l|}{ DEL } \\
\hline Positive & 14 & 19 & 0.202 \\
\hline Negative & 46 & 103 & \\
\hline
\end{tabular}

Abbreviations: COO: cell of origin; DEL: double expression lymphoma; ECOG PS: performance status of Eastern Cooperative Oncology Group; ENI: extranodal involvement; ESR: erythrocyte sedimentation rate; GCB: germinalcenter B-cell type; IPI: International Prognostic Index; LDH: lactate dehydrogenase; ULN: upper limit of normal

\section{Survival analysis of ESR}

To expand our findings, survival analyses were performed on the cohort. Similar to what was found for clinical features, ESR-positive patients showed significantly decreased OS compared to ESR-negative ones (2-year OS rate, $55.2 \%$ vs. $89.0 \%, p<0.001$ ) and PFS (2-year PFS rate, $37.5 \%$ vs. $60.3 \%, p<0.001$ ) (Fig. 1a-1b). Other clinical and pathological factors were also relevant to lower survival ratio, including Myc protein positivity, double expression lymphoma (DEL), B symptoms, ENI $\geq$ 2, elevated LDH level, poor PS, advanced Ann Arbor stage, high-risk IPI, and non-GCB subtype (Fig. 1c-1h, Fig. 2a-2h, Fig. 3a-3f). Multivariate analysis, including ESR and the above clinical and pathological parameters, found that abnormal ESR is one of the independent prognostic factors for OS (HR: $1.897 ; 95 \% \mathrm{CI}=1.180-$ $2.950 p=0.037$ ) and PFS (HR: 1.713; 95\% CI $=1.090$ $2.261 p=0.043$ ) (Table 3).

\section{Dynamic changes in ESR and clinical efficacy}

A total of 20 patients who completed 6 cycles of standard treatment were chosen for dynamic analysis. The association between ESR and clinical efficacy was analyzed in different treatment cycles. We noticed that ESR in most patients $(8 / 10)$ who achieved complete remission (CR) fell below the cutoff level after the first cycle and had never risen above $37.5 \mathrm{~mm} /$ hour again (Fig. 4a). Similarly, in the partial response (PR) group, the ESR of all patients (3/3) had dropped below the cutoff level after two or three cycles (Fig. 4a). In contrast, ESR of patients in the stable disease/progressive disease (SD/PD) group almost stayed above the cutoff levels or rebounded after the initial two cycles (Fig. 4b).

\section{Discussion}

In this study, we evaluated the prognostic value of ESR in DLBCL patients. Our results showed that ESR was a reliable factor predicting the outcome of DLBCL. ESR, obtained at diagnosis, is a novel and immediate prognostic factor in DLBCL patients. This is the first time that the prognostic value of serum ESR in DLBCL patients is discussed in the literature. ESR at diagnosis is significantly related high-risk clinical features in patients who received rituximab-based chemotherapy. In addition, ESR could be used as a monitoring biomarker. We provide evidence that a higher ESR is associated with poorer outcomes than lower ESR; these patients may require more aggressive treatment regimens.

Throughout the processes of most biological behaviors of cancer, inflammation plays an important role [21]. The first recognition of the relationship between inflammation and tumor growth was made in the nineteenth century, and is considered as one of the hallmarks of cancer [22]. An increasing amount of evidence indicates 

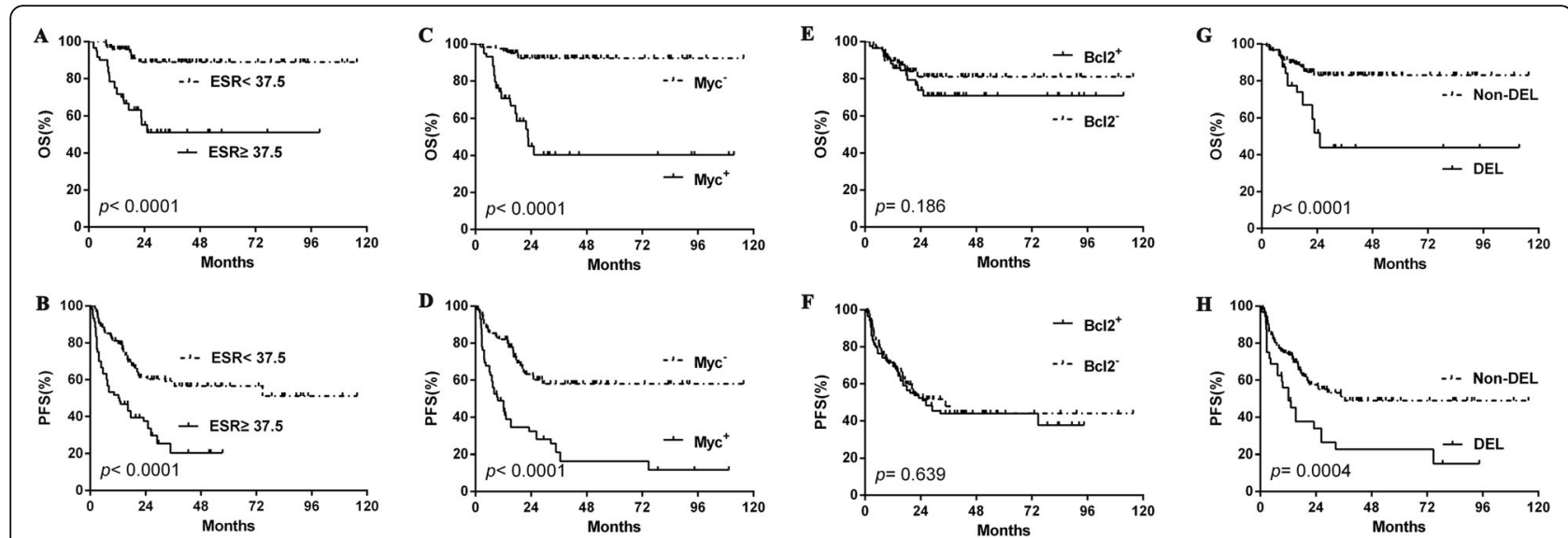

Fig. 1 The differences of overall survival and progression-free survival in cases grouped according to ESR (a-b), Myc protein positivity (c-d), Bcl2 protein positivity (e-f), and DEL (g-h). Abbreviations: ESR: erythrocyte sedimentation rate; OS: overall survival; PFS: progression-free survival; DEL: double expression lymphoma

that the majority of tumors are linked to chronic inflammation [23]. Chronic inflammation can give rise to a mutagenic microenvironment which is either initiating cancer transformation or promoting gene mutation [21].

It is widely accepted that close relationships exist between infection and diseases, such as of Helicobacter pylori infection and gastric cancer or mucosa-associated lymphoid tissue lymphoma; Hepatitis $B$ or $C$ viruses and hepatocellular carcinoma; and Schistosoma or Bacteroides and bladder or colon cancer [24-26]. Additionally, many non-specific inflammatory markers also participated in cancer development. For example, C-reactive protein is a biomarker of acute inflammation, while ESR is a marker of chronic inflammatory conditions [27]. Both play key roles in cancer development and progression [24], and persistent of chronic infection plays a more important role in cancer progression [21]. Therefore, ESR, a chronic inflammatory marker, is more suitable for tracking inflammation among patients with chronic conditions [8]. Cumulative research has shown that high ESR is a significant predictor for cancer-specific survival of solid tumors [12, 14, 16].

Recently, inflammatory processes have been identified to play an important role in the pathogenesis of lymphoma [28, 29], and circulating inflammatory parameters were associated with a poor prognosis in DLBCL $[8,30,31]$. A retrospective study showed that modified Glasgow prognostic scores (mGPS) could be used as a predictor in DLBCL treated with $\mathrm{R}-\mathrm{CHOP}$ regimens [27]. Patients with lower mGPS had higher CR rates and better OS. So far, few studies, including the above mGPS study, examined ESR, which is one

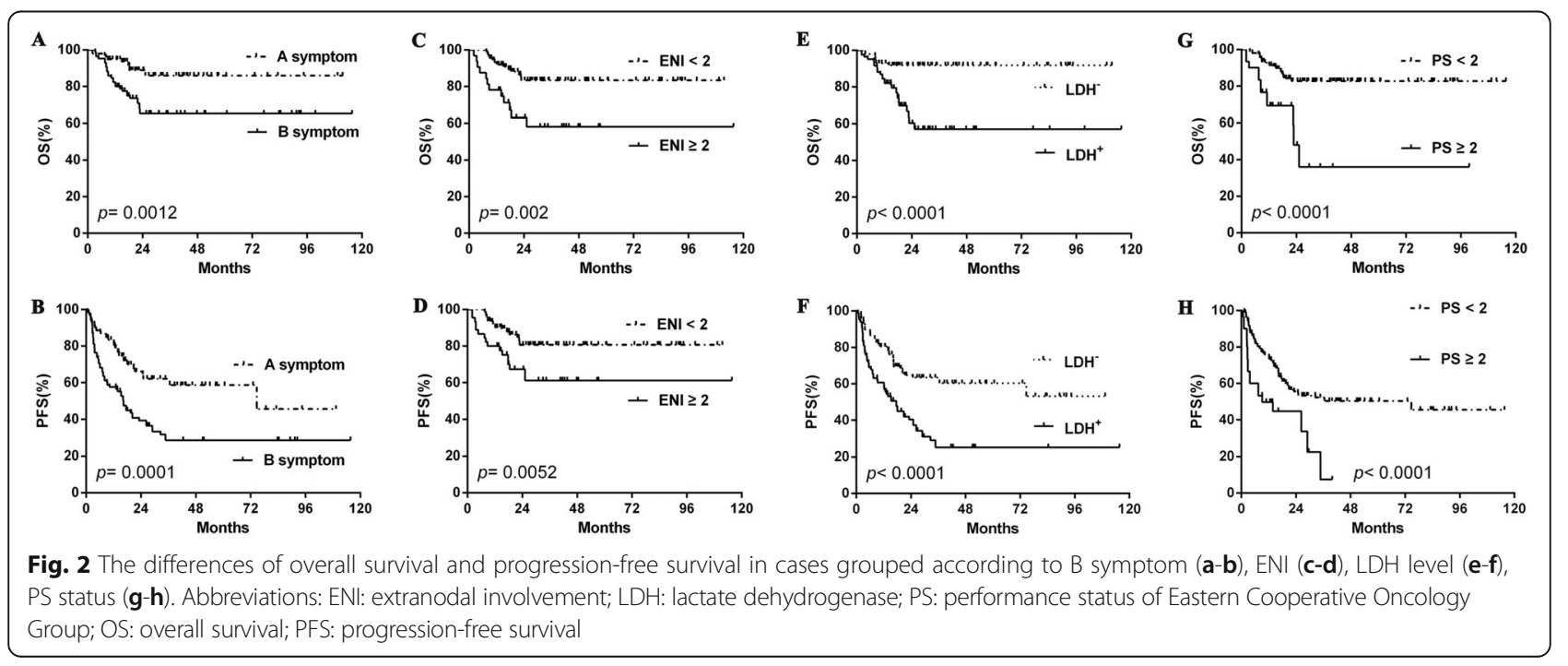




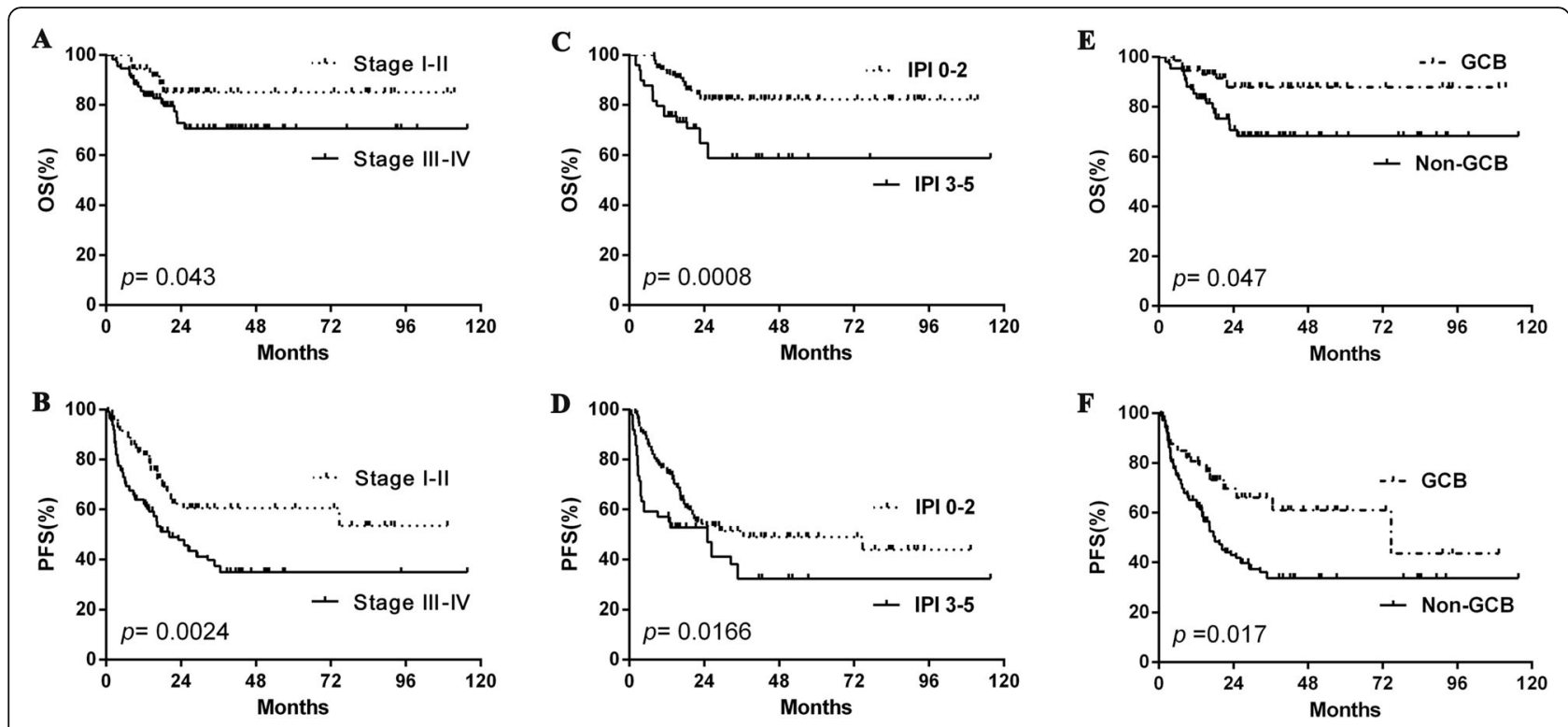

Fig. 3 The differences of overall survival and progression-free survival in cases grouped according to clinical stage (a-b), IPI risk stratification (c-d) and COO (e-f). Abbreviations: IPI: International Prognostic Index; GCB: germinal-center B-cell type; OS: overall survival; PFS: progression-free survival

of the most commonly used laboratory markers of chronic inflammation [27]. One preliminary case-control study evaluated the diagnostic value of ESR in differentiating active Crohn's disease (ACD) from intestinal lymphoma and discovered ESR was lower in the ACD group, compared with the lymphoma group [32], which indicated that ESR has a more important function in lymphoma development than other inflammatory disease. Another study analyzed several inflammation markers primary gastric DLBCL patients, including ESR, and ultimately considered beta-2 microglobulin, but not ESR, was related to poor outcomes in DLBCL patients [8]. Unfortunately, it was a rather small study that only included 49 patients, and the significance remains to be confirmed. Therefore, the prognostic value of serum ESR in patients with malignant lymphoma, especially
DLBCL, is still uncertain. Based on this, we enlarged the sample size, reanalyzed the prognostic value of ESR, and found that ESR is a powerful biomarker predicting poor prognosis for DLBCL patients.

As chronic inflammatory processes affect all stages of tumor development as well as therapy [21], only prognostic significance is just not enough. The dynamic change of chronic inflammatory marker on therapeutic effect evaluation and recurrence forecast seems to be more important. ESR has been confirmed to be helpful in monitoring chronic inflammatory conditions [27]. Elevated ESR is associated with increased mortality in patients with dermatomyositis due to respiratory failure [12]. Thus, monitoring ESR should be an integral part of the clinical care of dermatomyositis patients. In addition,

Table 3 Univariate and multivariate analysis of clinical factors for OS and PFS

\begin{tabular}{|c|c|c|c|c|c|c|c|c|}
\hline \multirow{3}{*}{$\begin{array}{l}\text { Variate } \\
\text { Non-GCB }\end{array}$} & \multicolumn{4}{|c|}{ multivariate analysis (OS) } & \multicolumn{4}{|c|}{ multivariate analysis (PFS) } \\
\hline & \multirow{2}{*}{$\begin{array}{l}\mathrm{HR} \\
0.746\end{array}$} & \multicolumn{2}{|l|}{$95 \% \mathrm{Cl}$} & \multirow{2}{*}{$\frac{P \text { value }}{0.531}$} & \multirow{2}{*}{$\begin{array}{l}\mathrm{HR} \\
1.630\end{array}$} & \multicolumn{2}{|c|}{$95 \% \mathrm{Cl}$} & \multirow{2}{*}{$\frac{P \text { value }}{0.076}$} \\
\hline & & 0.299 & 1.862 & & & 1.377 & 2.050 & \\
\hline Myc positivity & 1.629 & 1.057 & 3.291 & $<0.001$ & 1.650 & 1.227 & 2.540 & $<0.001$ \\
\hline B symptom & 1.509 & 1.235 & 2.104 & 0.088 & 0.710 & 0.425 & 1.184 & 0.190 \\
\hline ECOG PS $\geq 2$ & 0.708 & 0.568 & 1.015 & 0.528 & 0.937 & 0.521 & 1.687 & 0.829 \\
\hline $\mathrm{ENI} \geq 2$ & 0.494 & 0.195 & 1.251 & 0.137 & 1.623 & 1.236 & 2.760 & 0.004 \\
\hline Stage III-IV & 1.057 & 0.534 & 1.447 & 0.521 & 0.768 & 0.451 & 1.309 & 0.333 \\
\hline Elevated LDH & 1.891 & 1.221 & 2.178 & 0.094 & 1.774 & 1.437 & 2.371 & 0.079 \\
\hline IPI 3-5 & 2.070 & 1.088 & 2.550 & 0.046 & 2.071 & 1.066 & 3.025 & 0.032 \\
\hline $\mathrm{ESR} \geq 37.5 \mathrm{~mm} /$ hour & 1.897 & 1.180 & 2.950 & 0.037 & 1.713 & 1.090 & 2.261 & 0.043 \\
\hline
\end{tabular}

Abbreviations: ECOG PS: performance status of Eastern Cooperative Oncology Group; ENI: extranodal involvement; ESR: erythrocyte sedimentation rate; GCB: germinal-center B-cell type; $L D H$ : lactate dehydrogenase; IPI: International Prognostic Index; OS: overall survival; PFS: Progression-free survival 

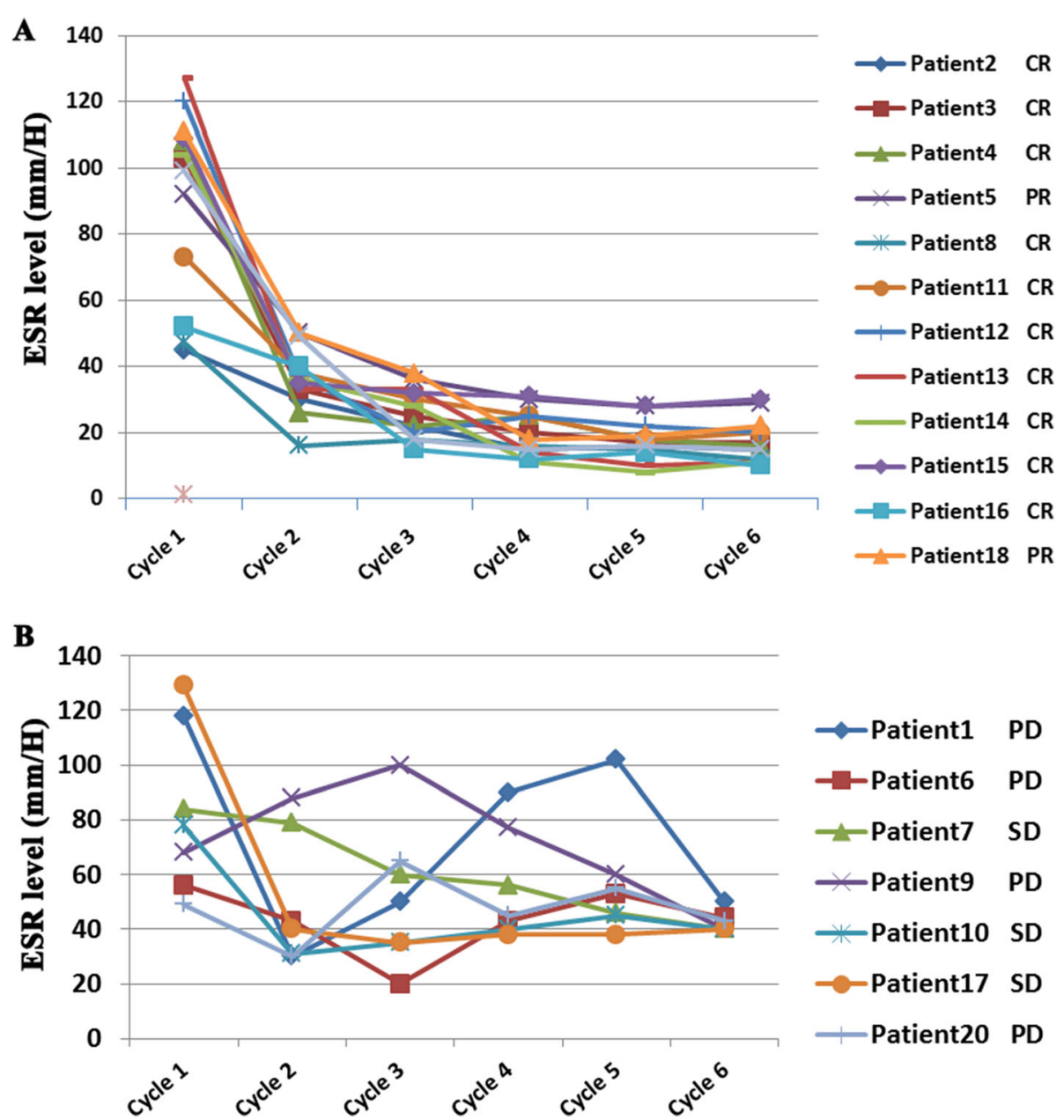

Fig. 4 Dynamic changes in ESR and clinical efficacy. ESR in most patients (8/10) who achieved CR fell below cutoff value after the first cycle and had never risen above $37.5 \mathrm{~mm} /$ hour again. Similarly, in PR group, ESR value of all the patients (3/3) were dropped below cutoff value after two or three cycles. In contrast, ESR of patients in the stable disease/ progressive disease (SD/PD) group almost stayed above cutoff value or rebounded after the initial two cycles. Abbreviations: CR: Complete remission; PR: Partial response; SD: Stable disease; PD: Progressive disease

dynamic change of the systemic immune inflammation index with hepatocellular carcinoma predicts prognosis after curative resection. In our study, we evaluated the dynamic change of ESR in DLBCL. We observed that ESR in most patients in the CR/PR group fell below the cutoff value after the initial cycles and was never above the cutoff value again, whereas ESR in patients in the $\mathrm{SD} / \mathrm{PD}$ group almost stayed above cutoff levels or rebounded after the initial cycles. We determined that ESR prior to treatment is a promising factor for monitoring treatment response and disease status.

\section{Conclusions}

This study is limited by its retrospective design and relatively small number of patients. Further prospective studies including more patients are required. In spite of these limitations, our study suggests that pretreatment ESR is associated with OS and PFS in DLBCL patients treated with immunochemotherapy. High ESR before treatment initiation was a reliable prognostic factor of unfavorable prognosis in DLBCL patients. Also, dynamic changes in ESR are valuable in assessing curative effect and predicting disease recurrence. Building on our findings, we recommend that ESR be used as an inexpensive biomarker for risk assessment in patients with DLBCL that can be determined without difficulty. Patients with high ESR after initial cycles might need more aggressive or second line therapies.

\section{Additional files}

Additional file 1: Figure S1. The optimal cutoff value was $39 \mathrm{~mm} /$ hour for ESR with OS according to X-tile. Abbreviations: ESR: erythrocyte sedimentation rate; OS: overall survival. (TIF $158 \mathrm{~kb}$ )

Additional file 2: Figure S2. The optimal cutoff value was $36 \mathrm{~mm} /$ hour for ESR with PFS according to X-tile. Abbreviations: ESR: erythrocyte sedimentation rate; PFS: progression-free survival. (TIF 154 kb) 


\section{Abbreviations}

ACD: Active Crohn's disease; CR: Complete remission; DEL: Double expression lymphoma; DLBCL: Diffuse large B cell lymphoma; ENI: Extranodal involvement; ESR: Erythrocyte sedimentation rate; HR: Hazard ratio; IPI: International prognostic index; LDH: Lactate dehydrogenase; mGPS: Modified Glasgow prognostic scores; NCCN-IPI: International prognostic index of national comprehensive cancer network; NHL: Non-Hodgkin lymphoma; OS: Overall survival; PD: Progressive disease; PFS: Progression-free survival; PR: Partial response; PS: Performance status; R-CHOP: Rituximab plus cyclophosphamide, doxorubicin, vincristine, and prednisone; SD: Stable disease; WHO: World Health Organization

\section{Funding}

This study was supported by National Natural Science Foundation of China (81600152), Jiangsu Province Natural Science Foundation (BK20160194), Jiangsu Province Young Medical Talents (QNRC2016155).

\section{Availability of data and materials}

The datasets generated and/or analyzed during the current study are available from the corresponding author on reasonable request.

\section{Authors' contributions}

SW, TXL and DH were responsible for conception and design. SW, YZ, HYH, YZ, WYZ, ZQW contributed to collection and assembly of data, SW and TXL performed the experiments. Data analysis and interpretation were performed by SW, YZ, HYH, YZ, JL, HQG, XHW, TXL and DH. SW and TXL wrote the manuscript. All authors read and approved the final manuscript. All authors contributed to the writing of the manuscript and provided final approval of the manuscript. All authors have read and approved the final version of this manuscript.

\section{Ethics approval and consent to participate}

The study was conducted in accordance with the Declaration of Helsinki principles. It was approved by the Human Research Ethics Committee of the Third Affiliated Hospital of Nantong University and Affiliated Hospital of Jiangnan University.

\section{Consent for publication}

Not applicable.

\section{Competing interests}

The authors declare that they have no competing interests.

\section{Publisher's Note}

Springer Nature remains neutral with regard to jurisdictional claims in published maps and institutional affiliations.

\section{Author details}

'Department of Hematology, The Third Affiliated Hospital of Nantong University, The Third People's Hospital of Wuxi, Wuxi 214000, Jiangsu, People's Republic of China. ${ }^{2}$ Department of Oncology, Affiliated Hospital of Jiangnan University, Wuxi 214000, Jiangsu, People's Republic of China.

\section{Received: 12 February 2018 Accepted: 8 October 2018} Published online: 19 October 2018

\section{References}

1. Friedberg JW, Fisher RI. Diffuse large B-cell lymphoma. Hematol Oncol Clin North Am. 2008;22(5):941-52.

2. Hans CP, Weisenburger DD, Greiner TC, Gascoyne RD, Delabie J, Ott G, Muller-Hermelink HK, Campo E, Braziel RM, Jaffe ES, et al. Confirmation of the molecular classification of diffuse large B-cell lymphoma by immunohistochemistry using a tissue microarray. Blood. 2004;103(1):275-82.

3. Ozturk E, Ozbalak M, Berk S, Erdogan I, Avsar E, Dolgun A, Cetiner M, Mandel NM, Yalniz FF, Elverdi T, et al. Comparison of international prognostic index and NCCN-IPI in 324 patients with de novo diffuse large B-cell lymphoma: a multi-center retrospective analysis. Leukemia \& lymphoma. 2016;57(5):1211-4.

4. Huang CE, Chen YY, Lu CH, Chen PT, Lee KD, Chen CC. Validation of an enhanced international prognostic index (NCCN-IPI) in an Asian cohort of patients with diffuse large B cell lymphoma. Ann Hematol. 2015;94(6):1063-5.
5. El-Galaly TC, Villa D, Alzahrani M, Hansen JW, Sehn LH, Wilson D, de Nully Brown P, Loft A, lyer $\mathrm{V}$, Johnsen $\mathrm{HE}$, et al. Outcome prediction by extranodal involvement, IPI, R-IPI, and NCCN-IPI in the PET/CT and rituximab era: a Danish-Canadian study of 443 patients with diffuse-large B-cell lymphoma. Am J Hematol. 2015;90(11):1041-6.

6. Montalban C, Diaz-Lopez A, Dlouhy I, Rovira J, Lopez-Guillermo A, Alonso S, Martin A, Sancho JM, Garcia O, Sanchez JM, et al. Validation of the NCCN-IPI for diffuse large B-cell lymphoma (DLBCL): the addition of beta2 -microglobulin yields a more accurate GELTAMO-IPI. Br J Haematol. 2017;176(6):918-28.

7. Eiro N, Vizoso FJ. Inflammation and cancer. World journal of gastrointestinal surgery. 2012;4(3):62-72.

8. Rotaru I, Gaman GD, Stanescu C, Gaman AM. Evaluation of parameters with potential prognosis impact in patients with primary gastric diffuse large Bcell lymphoma (PG-DLBCL). Romanian journal of morphology and embryology $=$ Revue roumaine de morphologie et embryologie. 2014; 55(1):15-21.

9. Choi ES, Kim HS, Han I. Elevated preoperative systemic inflammatory markers predict poor outcome in localized soft tissue sarcoma. Ann Surg Oncol. 2014;21(3):778-85.

10. Ma YM, Sun T, Liu YX, Zhao N, Gu Q, Zhang DF, Qie S, Ni CS, Liu Y, Sun BC. A pilot study on acute inflammation and cancer: a new balance between IFN-gamma and TGF-beta in melanoma. Journal of experimental \& clinical cancer research : CR. 2009;28:23-36.

11. Kantor ED, Udumyan R, Signorello LB, Giovannucci EL, Montgomery S, Fall K Adolescent body mass index and erythrocyte sedimentation rate in relation to colorectal cancer risk. Gut. 2016;65(8):1289-95.

12. Go DJ, Lee EY. Elevated Erythrocyte Sedimentation Rate Is Predictive of Interstitial Lung Disease and Mortality in Dermatomyositis. a Korean Retrospective Cohort Study. 2016;31(3):389-96.

13. Sung HH, Jeon HG, Jeong BC, Seo SI, Jeon SS, Choi HY, Lee HM. Clinical significance of prognosis using the neutrophil-lymphocyte ratio and erythrocyte sedimentation rate in patients undergoing radical nephroureterectomy for upper urinary tract urothelial carcinoma. BJU Int. 2015;115(4):587-94.

14. Strojnik T, Smigoc T, Lah TT. Prognostic value of erythrocyte sedimentation rate and C-reactive protein in the blood of patients with glioma. Anticancer Res. 2014;34(1):339-47.

15. Stojan $G$, Fang $H$, Magder $L$, Petri M. Erythrocyte sedimentation rate is a predictor of renal and overall SLE disease activity. Lupus. 2013;22(8):827-34.

16. Choi Y, Park B, Kim K, Jeong BC, Seo SI, Jeon SS, Choi HY, Lee JE, Lee HM. Erythrocyte sedimentation rate and anaemia are independent predictors of survival in patients with clear cell renal cell carcinoma. Br J Cancer. 2013; 108(2):387-94.

17. Hallermann C, Niermann C, Fischer RJ, Schulze HJ. Erythrocyte sedimentation rate as an independent prognostic factor in mycosis fungoides. Br J Dermatol. 2012;166(4):873-4

18. Sengupta S, Lohse CM, Cheville JC, Leibovich BC, Thompson RH, Webster WS, Frank I, Zincke H, Blute ML, Kwon ED. The preoperative erythrocyte sedimentation rate is an independent prognostic factor in renal cell carcinoma. Cancer. 2006;106(2):304-12.

19. Johnson NA, Slack GW, Savage KJ, Connors JM, Ben-Neriah S, Rogic S, Scott DW, Tan KL, Steidl C, Sehn LH, et al. Concurrent expression of MYC and BCL2 in diffuse large B-cell lymphoma treated with rituximab plus cyclophosphamide, doxorubicin, vincristine, and prednisone. J Clin Oncol. 2012;30(28):3452-9.

20. Cheson BD, Fisher Rl, Barrington SF, Cavalli F, Schwartz LH, Lister TA, Alliance AL, Lymphoma G, Eastern Cooperative Oncology G, European Mantle Cell Lymphoma C, et al. Recommendations for initial evaluation, staging, and response assessment of Hodgkin and non-Hodgkin lymphoma: the Lugano classification. J Clin Oncol. 2014;32(27):3059-68.

21. Elinav E, Nowarski R, Thaiss CA, Hu B, Jin C, Flavell RA. Inflammation-induced cancer: crosstalk between tumours, immune cells and microorganisms. Nat Rev Cancer. 2013;13(11):759-71.

22. Hanahan D, Weinberg RA. Hallmarks of cancer: the next generation. Cell. 2011;144(5):646-74.

23. Hagerling C, Casbon AJ, Werb Z. Balancing the innate immune system in tumor development. Trends Cell Biol. 2015;25(4):214-20.

24. Grivennikov SI, Greten FR, Karin M. Immunity, inflammation, and cancer. Cell. 2010;140(6):883-99.

25. Karin M. Nuclear factor-kappaB in cancer development and progression. Nature. 2006;441(7092):431-6. 
26. Wu S, Rhee KJ, Albesiano E, Rabizadeh S, Wu X, Yen HR, Huso DL, Brancati FL, Wick E, McAllister F, et al. A human colonic commensal promotes colon tumorigenesis via activation of T helper type $17 \mathrm{~T}$ cell responses. Nat Med. 2009;15(9):1016-22.

27. Litao MK, Kamat D. Erythrocyte sedimentation rate and C-reactive protein: how best to use them in clinical practice. Pediatr Ann. 2014;43(10):417-20.

28. Sagaert X, Van Cutsem E, De Hertogh G, Geboes K, Tousseyn T. Gastric MALT lymphoma: a model of chronic inflammation-induced tumor development. Nat Rev Gastroenterol Hepatol. 2010;7(6):336-46.

29. Loong F, Chan AC, Ho BC, Chau YP, Lee HY, Cheuk W, Yuen WK, Ng WS, Cheung HL, Chan JK. Diffuse large B-cell lymphoma associated with chronic inflammation as an incidental finding and new clinical scenarios. Modern pathology : an official journal of the United States and Canadian Academy of Pathology, Inc. 2010;23(4):493-501.

30. Sun F, Zhu J, Lu S, Zhen Z, Wang J, Huang J, Ding Z, Zeng M, Sun X. An inflammation-based cumulative prognostic score system in patients with diffuse large B cell lymphoma in rituximab era. BMC Cancer. 2018;18(1):5-12.

31. Hao X, Wei Y, Wei X, Zhou L, Wei Q, Zhang Y, Huang W, Feng R. Glasgow prognostic score is superior to other inflammation-based scores in predicting survival of diffuse large B-cell lymphoma. Oncotarget. 2017;8(44):76740-8.

32. Liu S, Ren J, Xia Q, Wu X, Han G, Ren H, Yan D, Wang G, Gu G, Li J.

Preliminary case-control study to evaluate diagnostic values of $\mathrm{C}$-reactive protein and erythrocyte sedimentation rate in differentiating active Crohn's disease from intestinal lymphoma, intestinal tuberculosis and Behcet's syndrome. Am J Med Sci. 2013;346(6):467-72.

Ready to submit your research? Choose BMC and benefit from:

- fast, convenient online submission

- thorough peer review by experienced researchers in your field

- rapid publication on acceptance

- support for research data, including large and complex data types

- gold Open Access which fosters wider collaboration and increased citations

- maximum visibility for your research: over $100 \mathrm{M}$ website views per year

At $\mathrm{BMC}$, research is always in progress.

Learn more biomedcentral.com/submissions 